\title{
Posterior reversible encephalopathy syndrome (PRES) and systemic lupus erythematosus: report of two cases
}

\author{
Aline de Souza Streck ${ }^{1}$, Henrique Luiz Staub², Caroline Zechlinski Xavier de Freitas ${ }^{1}$, \\ Luis Marrone ${ }^{3}$, Jaderson Costa ${ }^{4}$, Giovani Gadonski ${ }^{5}$
}

\begin{abstract}
The posterior reversible encephalopathy syndrome (PRES) is a novel entity clinically manifested by headache, changes of sensorium, seizures, and visual loss. PRES pathogenesis has not been fully clarified. The entity can be associated to a variety of clinical conditions, mainly hypertension, renal insufficiency and immunosuppressive therapy. A possible link of autoimmune disorders with PRES has been recently hypothesized. We herein describe two cases of systemic lupus erythematosus whereby PRES was triggered by different factors.
\end{abstract}

Keywords: systemic lupus erythematosus, neuropsychiatric manifestations, posterior encephalopathy syndrome.

(C) 2012 Elsevier Editora Ltda. All rights reserved.

A posterior leukoencephalopathy characterized by transient headache, changes of mental status, seizures, and visual loss was originally described in 1996; white-matter vasogenic edema of occipital, and parietal lobes was a remarkable feature of those 15 patients then reported. ${ }^{1}$ In 2000, Casey et al. ${ }^{2}$ proposed the term posterior reversible encephalopathy syndrome (PRES) for this entity.

The pathogenesis of PRES is not yet fully understood. Auto-regulatory failure with resultant vasodilatation, as seen in hypertensive encephalopathy, is often cited as the underlying mechanism. Vasospasm with ischemic abnormalities are also postulated. ${ }^{3}$ On magnetic resonance imaging (MRI), parietooccipital subcortical T2 hyperintensity without enhancement is typical. Other structures such as the brain stem, cerebellum, and frontal and temporal lobes may also be involved. Abnormalities of the subcortical white-matter are the rule, but the cortex and the basal ganglia are eventually affected. ${ }^{4}$
PRES could result from a number of associated morbidities, including autoimmune disorders. To date, the issue has been rarely addressed in the Rheumatology scenario. We herein describe two cases of PRES in patients with systemic lupus erythematosus (SLE).

Case 1: A 30-year-old Caucasian woman diagnosed with SLE at the age 19 was on methylprednisolone (MP) pulse therapy $1 \mathrm{~g} /$ daily due to an anti-DNA positive nephritis. On day four of the treatment the patient suddenly presented severe headache and right hemianopsia. Mental status was normal. At that time, her blood pressure was $160 / 80 \mathrm{mmHg}$ and her creatinine was $1.31 \mathrm{mg} / \mathrm{dL}$ (six months before the creatinine was $0.72 \mathrm{mg} / \mathrm{dL}$ ). Sodium and potassium levels were normal. A cranial computed tomography (CT) was unremarkable. A brain MRI with T2 and fluid-attenuated inversion recovery sequences (MRI-T2/FLAIR) showed a subcortical T2 hyperintensity without enhancement on both

Received on 11/01/2011. Approved on 06/27/2012. The authors declare no conflict of interest.

Department of Rheumatology, Hospital São Lucas, Pontifícia Universidade Católica do Rio Grande do Sul - PUCRS

1. Rheumatologist, Hospital São Lucas, Pontifícia Universidade Católica do Rio Grande do Sul - PUCRS

2. Rheumatologist; Professor of the Department of Rheumatology, Hospital São Lucas, PUCRS

3. Neurologist, Member of the Neurology Service of the Hospital São Lucas, PUCRS

4. Neurologist; Professor of the Department of Neurology of the Hospital São Lucas, PUCRS

5. Nephrologist, Member of the Nephrology Service of the Hospital São Lucas, PUCRS

Correspondence to: Henrique Luiz Staub. Av. Ipiranga, 6690/220 - Jardim Botânico. Porto Alegre, RS, Brazil. CEP: 90610-000. E-mail: henriquestaub@terra.com.br 
occipital lobes (Figure 1). MP pulse therapy was interrupted, and analgesics were prescribed. The vision abnormalities improved after 72 hours and resolved within five days. After ten days, the patient was asymptomatic. Three weeks later a new brain MRI-T2/FLAIR showed no subcortical or cortical T2 hyperintensity in the occipital region.

Case 2: A 39-year old Caucasian woman with SLE diagnosed two years before was on low-dose prednisone and therapy with azathioprine due to thrombocytopenia. Owing to a recent episode of severe hemolytic anemia (hemoglobin $1.7 \mathrm{~g} / \mathrm{L}$ ), the patient was submitted to MP pulse therapy and intravenous immunoglobulin infusion. Subsequently, a bacterial pneumonitis and a catheter infection required intensive care and a long in-patient stay. After recovery, the patient was discharged from Hospital in a good general state. A week later, the patient returned to Hospital due to an acute cholangitis, which demanded endoscopic treatment followed by cholecystectomy. Subsequently, the patient evolved with

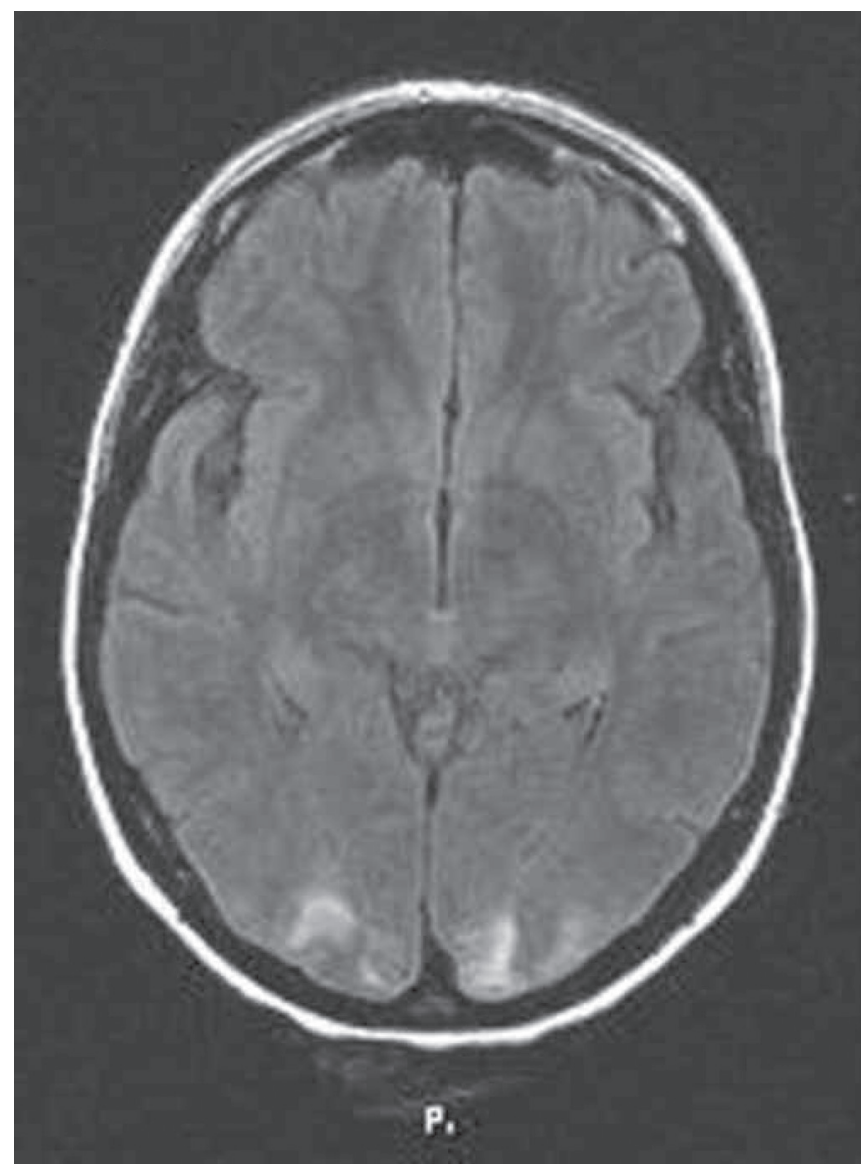

Figure 1

Brain MRI-T2/FLAIR showing subcortical T2 hyperintensity without enhancement in occipital lobes. multiple intra-hepatic abscesses. After two weeks in the infirmary receiving antibiotics, the patient, who had concomitant autoimmune hemolysis, showed elevation of blood pressure, headache, seizure, and mental confusion. A cranial CT was normal, as well as the cerebrospinal fluid exam. The cerebral MRI-T2/FLAIR revealed typical features of PRES in the subcortex of occipital and parietal lobes (Figure 2). Neurological improvement was obtained by adjusting blood pressure levels. A brain MRI carried out two weeks later showed impressive regression of findings attributable to PRES (Figure 3). After one month, the patient died due to a refractory sepsis.

PRES is an enigmatic disorder potentially triggered by a variety of conditions, most commonly hypertensive crisis, renal insufficiency, and immunosuppressive therapy. ${ }^{5}$ Other possible etiologies include eclampsia, ${ }^{6}$ transplantation, ${ }^{7}$ and systemic infections. ${ }^{8}$ A 58-year-old woman receiving gemcitabine and cisplatin chemotherapy for a gallbladder tumor developed PRES, according to a 2009 report. ${ }^{9}$ Our group recently described a case of a 74-year-old woman with pancreatic tumor who also developed PRES after gemcitabine therapy. ${ }^{10} \mathrm{Of}$

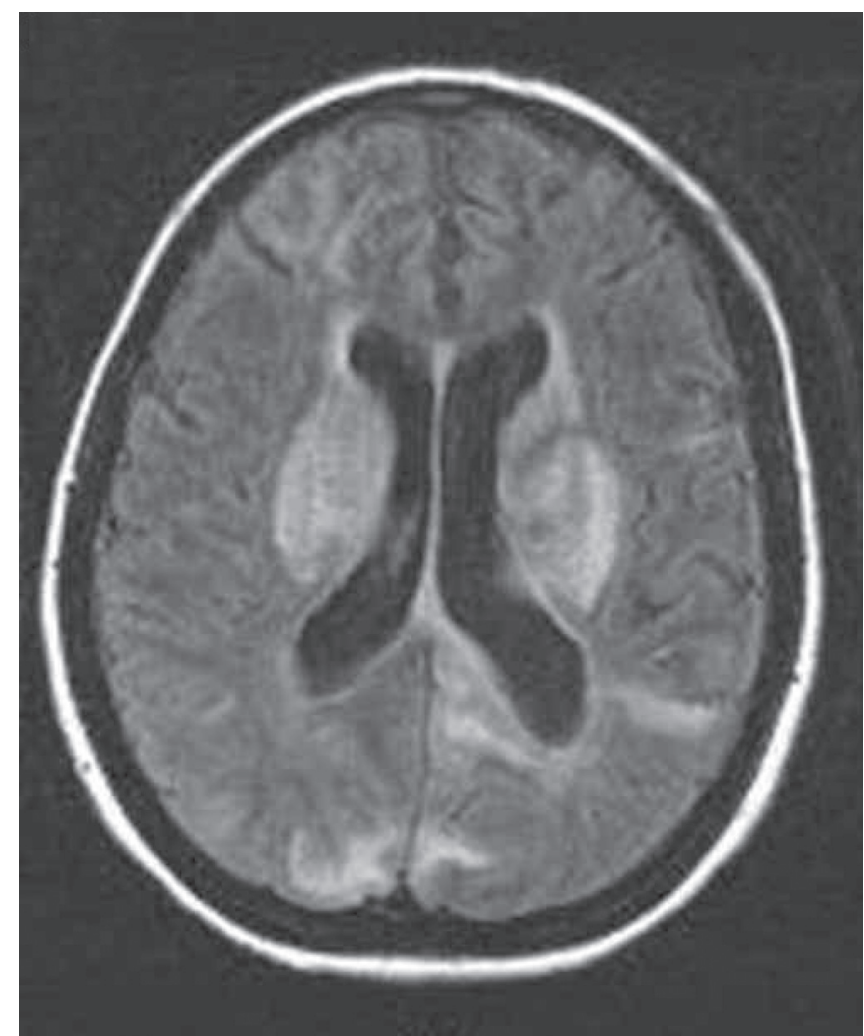

Figure 2

Brain MRI-T2/FLAIR showing T2 subcortical hyperintensity without enhancement in parieto-occipital lobes before treatment. 


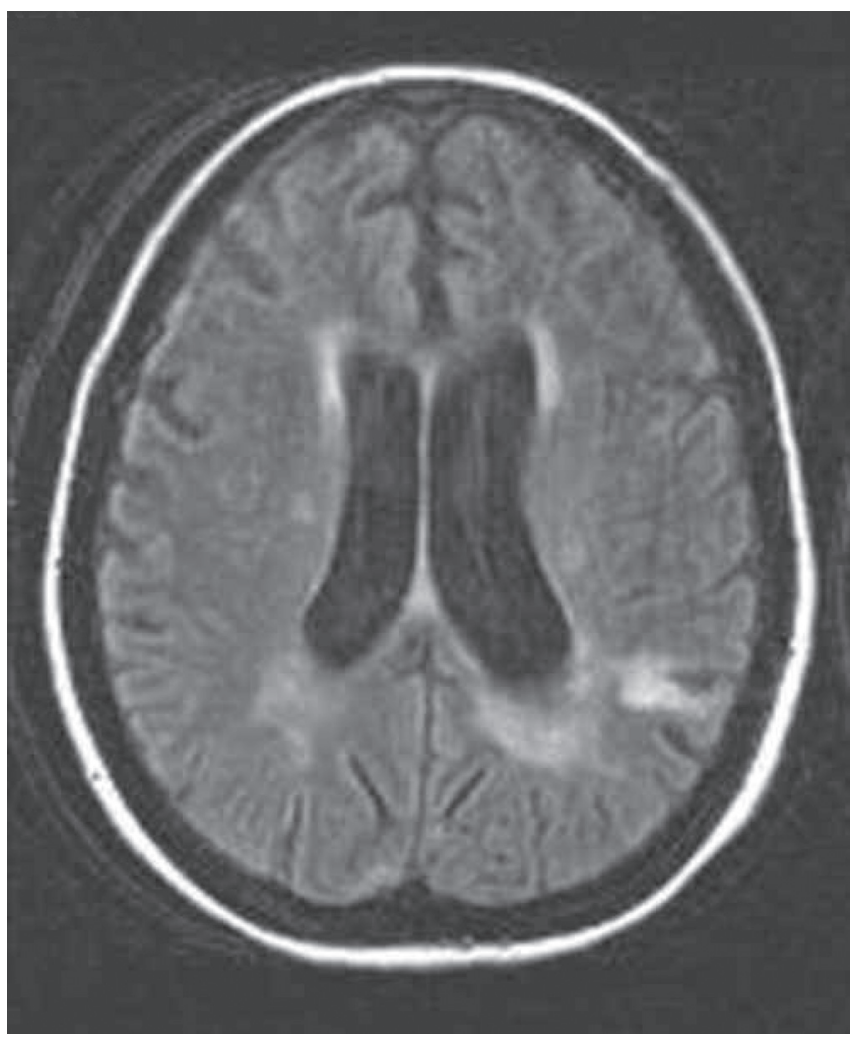

Figure 3

Brain MRI-T2/FLAIR after two weeks of treatment.

interest, in a series of 120 cases of PRES, autoimmune disorders were identified in $45 \%$ of the patients. ${ }^{11}$

The first description of PRES in SLE patients is as recent as 2006. The pathogenesis of PRES in patients with SLE is probably multifactorial: hypertension, nephritis, disease activity and immunosuppressive drugs have all been implicated. The distinctive role of immune mechanisms in the physiopathology of PRES can be clouded by these concurrent conditions. ${ }^{12}$

In the first case herein reported, PRES was diagnosed in a patient with active lupus nephritis undergoing MP pulse therapy. Both renal disease and MP infusion could be triggered PRES in this case, but the rapid neurological improvement after withdrawal of MP favored the last hypothesis. In the second patient, PRES appeared to be associated to active disease (hemolysis), infection (hepatic abscesses), and a hypertensive crisis, probably the latter being more relevant given the clinical response to anti-hypertensive drugs. Of interest, visual changes were present only in the first case. In the second case, differently from the first, parietal lesions were seen in addition to occipital changes.

Looking at the recent literature, PRES manifested by seizures and loss of vision was reported in a case of SLE in 2007. ${ }^{13}$ In 2008, four new cases of PRES were described in adults with SLE. ${ }^{14} \mathrm{~A}$ woman with lupus nephritis and PRES developed intraparenchymal and subarachnoid hemorrhage, according to a 2010 report. ${ }^{15}$ Recently, Balint syndrome (a disorder of inaccurate visually guided saccades, optic ataxia, and simultanagnosia) presented as PRES in a SLE patient. ${ }^{16}$ Of note, two reports accounted for the occurrence of PRES in juvenile SLE. ${ }^{17,18}$

Varaprasad et al. ${ }^{19}$ reviewed the features of 13 patients with SLE and PRES from 2006-2010: all had active disease and hypertension. Six patients had PRES as part of their initial presentation of SLE, and nine had nephritis. Four patients were on cyclophosphamide therapy when they developed PRES. ${ }^{19}$ Of interest, an association of PRES with lupus activity had already been postulated. ${ }^{11,20}$

Even though the classical neurolupus includes seizures and psychosis, a number of other features such as myelopathy, optic neuropathy, meningitis, cognitive dysfunction, and antiphospholipid-related cerebral infarction could been seen in SLE. ${ }^{21}$ PRES has been claimed as a particular form of neurological manifestation of SLE with characteristic MRI findings and a usual good outcome. Antihypertensive, antiepileptic, and supportive care are the mainstay of treatment. ${ }^{12,22}$

In summary, we herein report the first two cases of PRES in Brazilian patients with SLE. MP pulse therapy, disease activity, hypertension, and infection were possible triggers. In practical terms, patients with SLE presenting headache, altered sensorium, seizures and visual loss should be suspected of PRES. Whether the intrinsic mechanisms leading to PRES in SLE patients are associated to comorbidities or to the disease itself, it should be solved in the future. 


\section{REFERENCES}

1. Hinchey J, Chaves C, Appignani B, Breen J, Pao L, Wang A et al. A reversible posterior leukoencephalopathy syndrome. N Engl J Med 1996; 334(8):494-500. 
2. Casey SO, Sampaio RC, Michel E, Truwit CL. Posterior reversible encephalopathy syndrome: utility of fluid-attenuated inversion recovery MR imaging in the detection of cortical and subcortical lesions. AJNR Am J Neuroradiol 2000; 21(7):1199-206.

3. Schwartz RB. Hyperperfusion encephalopathies: hypertensive encephalopathy and related conditions. Neurologist 2002; 8(1):22-34.

4. Lamy C, Oppenheim C, Méder JF, Mas JL. Neuroimaging in posterior reversible encephalopathy syndrome. J Neuroimaging 2004; 14(2):89-96.

5. Petrović B, Kostić V, Sternić N, Kolar J, Tasić N. Posterior reversible encephalopathy syndrome. Srp Arh Celok Lek 2003; 131(11-12):461-6.

6. Schwartz RB, Feske SK, Polak JF, DeGirolami U, Iaia A, Beckner KM et al. Preeclampsia-eclampsia: clinical and neuroradiographic correlates and insights into the pathogenesis of hypertensive encephalopathy. Radiology 2000; 217(2):371-6.

7. Bartynski WS, Tan HP, Boardman JF, Shapiro R, Marsh JW. Posterior reversible encephalopathy syndrome after solid organ transplantation. AJNR Am J Neuroradiol 2008; 29(5):924-30.

8. Bartynski WS, Boardman JF, Zeigler ZR, Shadduck RK, Lister J. Posterior reversible encephalopathy syndrome in infection, sepsis, and shock. AJNR Am J Neuroradiol 2006; 27(10):2179-90.

9. Kwon EJ, Kim SW, Kim KK, Seo HS, Kim do Y. A case of gemcitabine and cisplatin associated posterior reversible encephalopathy syndrome. Cancer Res Treat 2009; 41(1):53-5.

10. Marrone LC, Marrone BF, de la Puerta Raya J, Gadonski G, da Costa JC. Gemcitabine monotherapy associated with posterior reversible encephalopathy syndrome. Case Rep Oncol 2011; 4(1):82-7.

11. Fugate JE, Claassen DO, Cloft HJ, Kallmes DF, Kozak OS, Rabinstein AA. Posterior reversible encephalopathy syndrome: associated clinical and radiologic findings. Mayo Clin Proc 2010; 85(5):427-32.

12. Kur JK, Esdaile JM. Posterior reversible encephalopathy syndromean underrecognized manifestation of systemic lupus erythematosus. J Rheumatol 2006; 33(11):2178-83.
13. Ozgencil E, Gülücü C, Yalçýn S, Alanoğlu Z, Unal N, Oral M et al. Seizures and loss of vision in a patient with systemic lupus erythematosus. Neth J Med 2007; 65(7):274.

14. Leroux G, Sellam J, Costedoat-Chalumeau N, Le Thi Huong D, Combes A, Tieulié N et al. Posterior reversible encephalopathy syndrome during systemic lupus erythematosus: four new cases and review of the literature. Lupus 2008; 17(2):139-47.

15. Chen HA, Lin YJ, Chen PC, Chen TY, Lin KC, Cheng HH. Systemic lupus erythematosus complicated with posterior reversible encephalopathy syndrome and intracranial vasculopathy. Int J Rheum Dis 2010; 13(4):e79-82.

16. Kumar S, Abhayambika A, Sundaram AN, Sharpe JA. Posterior reversible encephalopathy syndrome presenting as Balint syndrome. J Neuroophthalmol 2011; 31(3):224-7.

17. Punaro M, Abou-Jaoude P, Cimaz R, Ranchin B. Unusual neurologic manifestations (II): posterior reversible encephalopathy syndrome (PRES) in the context of juvenile systemic lupus erythematosus. Lupus 2007; 16(8):576-9.

18. Muscal E, Traipe E, de Guzman MM, Myones BL, Brey RL, Hunter JV. MR imaging findings suggestive of posterior reversible encephalopathy syndrome in adolescents with systemic lupus erythematosus. Pediatr Radiol 2010; 40(7):1241-5.

19. Varaprasad IR, Agrawal S, Prabu VN, Rajasekhar L, Kanikannan MA, Narsimulu G. Posterior reversible encephalopathy syndrome in systemic lupus erythematosus. J Rheumatol 2011; 38(8):1607-11.

20. Baizabal-Carvallo JF, Barragán-Campos HM, Padilla-Aranda HJ, Alonso-Juarez M, Estañol B, Cantú-Brito C et al. Posterior reversible encephalopathy syndrome as a complication of acute lupus activity. Clin Neurol Neurosurg 2009; 111(4):359-63.

21. Hanly JG. Neuropsychiatric lupus. Rheum Dis Clin North Am 2005; 31(2):273-98.

22. Ishimori ML, Pressman BD, Wallace DJ, Weisman MH. Posterior reversible encephalopathy syndrome: another manifestation of CNS SLE? Lupus 2007; 16(6):436-43. 